Revista de la red interuniversitaria de estudios sobre las literaturas rioplatenses contemporáneas en Francia

$19 \mid 2018$

La rebelión de los hijos: el judaísmo en la literatura latinoamericana contemporánea entre tradición y asimilación

\title{
El escritor judío en Estados Unidos
}

\section{Karl Shapiro}

Traductor: Edgardo Dobry

\section{OpenEdition}

\section{Journals}

Edición electrónica

URL: http://journals.openedition.org/lirico/6863

DOI: 10.4000/lirico.6863

ISSN: 2262-8339

Editor

Réseau interuniversitaire d'étude des littératures contemporaines du Río de la Plata

Referencia electrónica

Karl Shapiro, «El escritor judío en Estados Unidos», Cuadernos LIRICO [En línea], 19 | 2018, Puesto en línea el 20 enero 2019, consultado el 01 mayo 2019. URL : http://journals.openedition.org/lirico/6863 DOI : $10.4000 /$ lirico.6863

Este documento fue generado automáticamente el 1 mayo 2019.

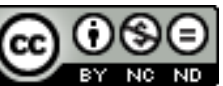

Cuadernos LIRICO está distribuido bajo una Licencia Creative Commons Atribución-NoComercialSinDerivar 4.0 Internacional. 


\title{
El escritor judío en Estados Unidos
}

\author{
Karl Shapiro
}

Tradución : Edgardo Dobry

\section{NOTA DEL EDITOR}

En nombre de Cuadernos LIRICO agradecemos la autorización para publicar esta traducción. Procedencia: "The Jewish Writer in America", In Defense of Ignorance, New York, Vintage Books, 1965, p. 205-217. Las cursivas son siempre del autor. La traducción de las citas entre comillas siempre es del traductor. Las notas y comentarios del traductor irán entre corchetes.

1 Durante la escritura de los capítulos de este libro, y de su eventual lectura en forma de conferencias, cobré consciencia de la desagradable necesidad de definir mi judaísmo ante el lector. ¿Qué tiene que ver el hecho de que yo sea judío con la crítica literaria? Bastante, según parece. El mero hecho de tener que defenderme frente al superficial antisemitismo de Pound o el profundo racismo de Eliot constituyen, desde ya, una posición. Y, en la medida en que tengo una posición, esta tiene necesariamente algo que ver con una "posición judía". Cuando tuve la ocasión de pronunciar estos escritos como conferencias fui acusado de criticar la poesía moderna desde un territorio "judío". Un profesor de filosofía abandonó airadamente un aula llena mientras yo hablaba desfavorablemente de Eliot; más tarde dijo que mis observaciones sobre el anglocatolicismo de Eliot lo ofendieron personalmente. La antifilosófica huida de este caballero allanó el camino a las críticas que vengo oyendo, desde entonces, con frecuencia: mi disputa con la escuela Pound-Eliot es una disputa judía. Me veo en la obligación de defender mi libro contra tales acusaciones. Y, en consideración a mis lectores "religiosos", debo explicar mi judaísmo, tal como es.

2 Una de las principales estrategias triunfales del nuevo clasicismo ha sido su capacidad para aplastar toda oposición, ya sea literaria, sociológica o religiosa. Eliot se esmeró en 
adular el pensamiento conservador en política, filosofía y religión. Pound mostró sus preferencias por la cultura aristocrática y por el autoritarismo político que va de la mano de la religión de la cultura. El antiamericanismo de ambos escritores es de esa variedad que vincula el mercantilismo con el "gusto popular" y el "librepensamiento". Lo que Eliot llama el "librepensamiento" judío corresponde, en Pound, a la banca judía internacional. Se trata, en efecto, de la imagen medieval del judío como Shylock y asesino de Cristo, que los clasicistas perpetúan en el siglo XX. Y, cosa digna de ser observada, el intelectual judío no se resiste a esa imagen sino que tiende a aceptar su culpa. Me refiero, en particular, a editores judíos de revistas culturales que alimentan un antisemitismo marxista-freudiano (basado en la idea de que la identidad judía es un anacronismo histórico), y me refiero también a muchos profesores judíos de literatura que forman parte del New Cristicism ${ }^{1} \mathrm{y}$ que, por consiguiente, se privan de emitir cualquier tipo de juicio humanístico. El libro de poemas que publiqué el año pasado, titulado Poemas de un judión ${ }^{2}$ fue atacado amargamente por los New critics judíos, en tanto que la prensa judía no intelectual aceptó, en general, los poemas como una torpe pero seria expresión de judaísmo moderno.

3 Una entera facción de profesores, críticos y editores judíos se ha dejado llevar por la nariz, mansamente, hacia el dominio Pound-Eliot. Aceptaron con satisfacción la religión de la Cultura que, en la crítica de Eliot, subsume aparentemente a toda religión verdadera. Aceptaron con satisfacción las ideas eliotianas de segunda mano acerca de la "cultura plural" que, aparentemente, subsume al simple nacionalismo. Fueron precisamente los "librepensadores" despreciados por Eliot quienes se volvieron sus más firmes defensores. Aquellos intelectuales que no quedaron cautivados por la versión eliotiana de la Tradición cayeron bajo el influjo de su estética de la "objetividad" en el arte. Incluso un crítico tan políticamente comprometido como F. O. Matthiessen se persuadió a sí mismo de que hubiera sido indecente dejar las creencias de Eliot al descubierto. Tan sagrada era la reputación de Eliot como poeta, pensador y hombre que la crítica sobre su obra se volvió el principal tabú del siglo XX. William Carlos Williams fue el único que se atrevió a atacar al amo. Para un judío, levantar la voz contra Pound, Eliot o Hulme era considerado un acto de brutalidad por el New Criticism y la Nueva Pedagogía. Resulta impresionante observar cómo buena parte de los defensores de Pound se apoyaron hipócritamente en cimientos "cristianos". Con qué alivio los intelectuales se aprovecharon del vulgar y ostentoso "canto" sobre la humildad para probar la pureza de corazón del viejo Ezra. Pound en el trono de la humildad contrarrestaba a Pound como Gran Dictador.

4 Como escritor estadounidense del siglo XX crecí en el respeto por la tradición literaria británica por encima de toda otra y participé de la famosa "culpa" americana acerca de nuestra herencia. Como judío, recibí la mala influencia de los intelectuales judíos, exmarxistas y freudianos, que minimizaban o incluso aceptaban el nuevo antiamericanismo y antisemitismo de los Modernos. Con mucha probabilidad nunca hubiera llegado a examinar las ideas de esos Modernos de no haber sido por mi participación en el affair del premio Bollingen concedido a Pound ${ }^{3}$, y por el hecho de haber enseñado poesía moderna. La consciencia judía que poseo hoy deriva precisamente de los escritos de los Clasicistas estadounidenses que insistieron todo lo posible en hacer de "americano" y "judío" dos males gemelos. Esa consciencia de mí mismo como judío estadounidense restringió y limitó mi escritura durante años, erigiendo un gueto privado en mi mente. La intención de romper con ese gueto es uno de los motivos por los que escribo este libro. 
$5 \quad$ No hay un escritor judío per se en Estados Unidos. El escritor estadounidense, en términos generales, no hace mención de sus ancestros, incluso aunque los conozca bien. El escritor estadounidense tiende a olvidarse de su pasado, cuando no a mofarse de él. Hay excepciones, por supuesto -los Henry Jameses y los Eliots-, pero la mayoría de los escritores estadounidenses adhieren al punto de vista de Mark Twain: todos esos duques, reyes y antepasados son pecios y desechos de los que uno haría muy bien en deshacerse. Un poeta de una vieja familia de Nueva Inglaterra me escribió cuando salió mi libro Poemas de un judío para decirme: “¡Tú te vas mucho más atrás que yo!”. Lo decía casi con un sentimiento de envidia, según creo. A continuación añadía, críptico: "Escribes como un árabe", uno de los elogios más raros que he recibido en mi vida. Bueno, siempre y cuando se tratara de un elogio.

6 Solo en la última o dos últimas generaciones un judío estadounidense puede escribir judaicamente y seguir siendo considerado estadounidense. Hace veinte años, cuando empecé a colaborar en revistas, escribí a un poeta de quien sabía que era judío y le pregunté cuáles eran los obstáculos con los que podía encontrarme para publicar poemas bajo un nombre judío. Su respuesta fue tan ambigua que decidí que su nombre, después de todo, no sonaba tan judío. No eran imaginaciones mías: muchos años más tarde un poeta no judío me dijo: "La primera vez que vi tus poemas pensé que tenías un nombre imposible para un poeta". La observación no era fruto del antisemitismo ni nada por el estilo sino que sugería la persistencia de la tradición británica en las letras estadounidenses hasta una época muy tardía. Tuve la impresión de que estaba haciendo un trabajo, en cierta medida, pionero para los escritores estadounidenses: el cambio de nombre siempre me resultó algo escandaloso, a pesar de ser una práctica común entre los escritores. En poesía o en cualquier otro arte, la cuestión de la raza o la religión tiene un enorme significado. En la actualidad el escritor judío estadounidense no se encuentra con obstáculos en tanto judío a la hora de publicar o para cualquier otra forma de reconocimiento, y esa circunstancia feliz hace que nos acerquemos aún más a la cuestión: ¿qué es un escritor judío estadounidense?

7 Desde mi punto de vista, la respuesta es: un escritor judío estadounidense es un judío que es estadounidense y es escritor. Todo el mundo sabe lo que es un estadounidense; todo el mundo sabe lo que es un escritor; pero muy pocas personas parecen saber lo que es un judío, incluyendo a los propios judíos, incluyendo a los escritores judíos estadounidenses.

8 Hace unos años participé en un congreso titulado "El escritor judío y la tradición literaria inglesa”. Se publicó en Commentary, que es en sí mismo una especie de fenómeno: una revista de clase media alta patrocinada por una organización judía estadounidense y por la dirección intelectual de la Partisan Review. El interrogante para el congreso era este: "Como judío y como escritor en la tradición anglo-americana, ¿cómo aborda la presencia, en esa tradición, de la figura mítica del judío tal como se encuentra en los pasajes (antisemitas) de Chaucer, Marlowe, Shakespeare, Scott, T.S. Eliot, Evelyn Waugh, Thomas Wolfe, Henry Adams, etc.? ¿En qué aspecto cree que eso representa un problema para usted, etc.?"

9 Leyendo entre líneas, creo que el sentido de la pregunta era este: ¿cree que un judío será capaz de entrar en la alta sociedad literaria? Es decir, se nos había formulado una pregunta sociológica, en la que no faltaba ninguno de los elementos de la mística judía. Y las respuestas también me parecieron sociológicas o, como decimos con frecuencia, racionalistas. Las respuestas se alinearon de la siguiente manera:

a) El judío defiende una cultura plural; por eso es atacado como "internacional". (El 
término "plural" fue popularizado por T.S. Eliot, a quien buena parte de los participantes en el congreso se sintió en la obligación de hacerle una reverencia como al pasar).

b) El antisemitismo es patológico, una enfermedad como la peste negra, y tan medieval como ella. Construyan una sociedad bien informada y esa plaga desaparecerá.

c) Los judíos también son, secretamente, antisemitas, provincianos y autocomplacientes. Los escritores judíos deberían ser más cosmopolitas.

d) Los escritores como Eliot en verdad aman a los judíos; solo hace falta saber interpretar sus insultos.

e) ¿Es el antisemitismo realmente real? (Esa fue la respuesta de Stephen Spender). Si el judío no supiera que es judío no creería que es judío.

El resumen de las otras posiciones corrió a cargo de Phikip Rahv, un lógico honesto e inflexible. Lo que debemos hacer, dijo Rahv, es "luchar contra la nueva religiosidad, junto con los intelectuales no judíos que rechazan el abandono de la perspectiva progresista y secular. Esa... religiosidad tiende a dividir antes que a unir a la humanidad; está históricamente vacía y metafísicamente impregnada de nostalgia...".

11 La mejor declaración en esta lista de respuestas fue la de Harold Rosenberg, quien apuntó a la debilidad de la propia pregunta. Rosenberg notó que ir de las personificaciones tipo Shylock al cliché sociológico es un grave error. Por ejemplo, algunos críticos alemanes ven $E l$ mercader de Venecia con el repulsivo Shylock y escriben una reseña que dice, en efecto: abajo los judíos. Así es como Shylock se vuelve el judío-con-el-cuchillo y un instrumento para la propaganda política. Como resultado de todo ello los judíos tienden a acusar a Shakespeare de antisemitismo.

Desde mi punto de vista, el congreso careció de sentido porque dio por sentado que la religión está obsoleta y que el racismo es una consecuencia de la religión. Los escritores que tomaron parte en él parecían decir que la religión es el mal y la cultura, el bien (cualquiera sea el significado que demos a "cultura"). Salvemos la cultura y deshagámonos de la religión.

Mi propia respuesta es esta: somos judíos por el consenso popular de la comunidad judeocristiana y no por elección o ambición. Aceptamos nuestro judaísmo porque rechazarlo sería una traición no a nuestros electores sino a nosotros mismos. Del mismo modo, creo que si no hubiera cumplido con mis obligaciones militares cuando fui reclutado hubiera traicionado $\mathrm{mi}$ identidad como estadounidense $\mathrm{e}^{4}$. Si esto es americanismo negativo entonces puedo llamarme a mí mismo, también, un judío negativo. Pero mi elección por Estados Unidos y por Israel me da una identidad completa, el tipo de identidad compuesta cuya supervivencia nunca se permitió en la historia de Europa.

14 El aspecto más curioso del asunto lo representan los judíos que son escritores reconocidos y que de alguna manera renuncian al judaísmo pero defienden, aunque sin mucho entusiasmo, su derecho a ser judíos. En el sentido de que verían con buenos ojos la extinción del judaísmo como religión al mismo tiempo que mantendrían su identidad como judíos. Reconozco que me excede la explicación acerca de cómo podría suceder tal cosa; tampoco sé qué sentido tendría. Leí en alguna parte que un escritor cristiano preguntó a un judío qué significaba ser judío. El judío le contestó: somos una religión. Es una bonita respuesta y sin duda verdadera, pero acaso no es suficiente. También somos más que una religión. 
15 En el congreso al que me refiero, la gente pareció interpretar la expresión "escritor judío estadounidense" como algo que insertaba en el idioma estadounidense algo del idioma judío o algo de la psicología judía. Desde mi punto de vista, se trata de una trivialidad; en todo caso, el idioma estadounidense es un amplio complejo de otros idiomas, todos los cuales tienden a hacer la gran literatura nacional de Estados Unidos. Una novela brillante como Las aventuras de Augie March de Saul Bellow está saturada de ocurrencias y sentimientos judíos; el mismo lenguaje sirve casi como transliteración o... no sabría cómo definirlo. Me refiero a que no sé idish pero puedo reconocer el idioma. Tampoco el lector estadounidense necesita reconocer la presencia de ese elemento en las novelas de Bellow porque, a esta altura, eso es tan estadounidense como judío. Lo verdaderamente judío en Bellow es mucho más profundo: es la poesía del judío lo que hace de su héroe lo que es, en Chicago, en México, donde sea que Augie esté. Bellow tradujo del idish el cuento de Singer "Gimpel el tonto". Es uno de los cuentos más cómicos y sin embargo más dolorosos que yo haya leído en mi vida, pero podría haber sido escrito en Nueva York en lugar de Polonia, o donde sea que se originó esa historia. Se trata del judaísmo mucho más allá de la cultura, los problemas sociales, la historia y todo lo demás. Está incluso más allá de la religión, tan lejos como yo sea capaz de ver.

El judaísmo social me parece algo del todo inútil; y la preservación de la memoria nacional por sí misma, una forma de mero narcisismo. El desafío del escritor judío no es quejarse de la sociedad sino elevarse por encima de esas quejas. Casi toda la literatura de protesta social es superficial; las realidades fundamentales de la diferencia están siempre más allá de las disputas ideológicas. Quiero decir que hay dos tipos de literatura judía estadounidense, el tipo recomendado en aquel congreso -una literatura psicológicamente judía- y el tipo verdadero, que es el que yo recomiendo: la literatura centrada en Dios. Es una manera pobre de decirlo, pero intentaré explicar a qué me refiero.

Una literatura meramente judaica es solo un tipo "regional" de literatura, incluso cuando esa "región" ocupe buena parte del mundo y de la historia. En esa literatura el judío puede ser bueno o malo, Shylock o el Judío Errante o Leopold Bloom, pero es simplemente un hombre con memoria, un anacronismo. No es el judío "que vive", como dijo Martin Buber. Es el judío del pasado, el judío del Muro de las Lamentaciones. Hace poco leí el nuevo Oxford Book of Irish Verse y quedé sorprendido por la cantidad de centenarios intentos por recuperar la condición de irlandeses, de apartarse del cosmopolitismo del escritor mundial y renovar una consciencia particular, que no es una "herencia cultural" sino una identidad. En el caso de los irlandeses solo puedo tener una vaga idea de lo qué cosa sea su identidad. Pero sí la conozco para el caso del judío. El escritor judío, en cualquier parte del mundo moderno, tiene el problema de recuperar la consciencia judía, que en nuestro caso es una consciencia de Dios. No estoy hablando de religión; la religión es solo el producto de esa consciencia. Al escritor judío que quiera dar la espalda a esa consciencia solo podemos darle nuestra bendición y dejarlo ir. Pero para el escritor judío consciente, en Estados Unidos o en cualquier otra parte, debemos señalar su obligación de establecer esa consciencia en un lugar central en su obra; se trata del derecho, por así decir, a la existencia de Dios. Esto podría animar el crecimiento de la religión; pero no estoy hablando de religión. No estoy a favor de ninguna religión institucionalizada, incluido el judaísmo.

La inteligencia creativa de los judíos ha recorrido distintos caminos durante siglos. Apenas estamos empezando a volver a la era de la filosofía judía, pero nuestro pensamiento abstracto pertenece todavía a la Edad Media. Produjimos un Einstein, quien, 
desde el punto de vista religioso o incluso político, es un bebé. Produjimos un Freud, quien impuso al mundo una religión subrogada mientras se esforzó fuertemente en destrozar tanto al cristianismo como al judaísmo en un solo movimiento. El fantástico poder intelectual de los judíos, en nuestro tiempo, está por todas partes excepto en la consciencia judía o, para usar una palabra un tanto arrogante, en la santidad.

Los judíos han escrito uno de los mayores libros sagrados. Ese libro es el principio y el final de nuestra literatura. La literatura judía no es grande. La filosofía judía no es grande. La erudición judía -quizás. Nuestra contribución a la ciencia, el gobierno, a las leyes y las humanidades, incluso al arte y la música, y, en nuestro tiempo, la pintura, fue fomentada por judíos. Pero el gran arte de la palabra escrita no fue fomentada por el pueblo del Libro. Al menos, no en un grado significativo.

Nuestros amigos del congreso sobre el escritor judío en Estados Unidos estaban más interesados en establecer nuevos símbolos literarios que en entender la religión o buscar la contracara mística de esta. Consecuentemente, pienso en ellos como escaladores de la sociedad literaria y no como poetas.

21 Hasta donde uno pueda hablar de estas cosas, solo hay dos países en el mundo en los que el escritor judío es libre de crear su propia consciencia: Israel y Estados Unidos ${ }^{5}$. En cualquier otro lugar el judío parece vivir en el pasado. Incluso la recreación que hizo Proust de nuestra consciencia es una especie de nostalgia judía. En Europa se trata o bien de una nostalgia o bien de una pesadilla: Proust o Kafka. El judío europeo siempre fue un visitante y lo sabía. Pero en Estados Unidos todo el mundo es un visitante. En esa tierra de visitantes permanentes el judío se encuentra en la peculiar posición de "viviente" en una plena consciencia judía. La vida judía es una gran paradoja histórica: somos aborígenes espirituales del mundo moderno, y somos la consciencia ética y, en ocasiones, intelectual del mundo moderno. La historia nos ha aborrecido tan profundamente porque cada judío ha sido visto como un testigo viviente de las revelaciones de cristianos y musulmanes -y, en efecto, así es. La aceptación, por parte del judío, de la santidad, y su actitud de laissez faire hacia la religión hace de él un blanco natural casi en cualquier situación histórica. Solo en Estados Unidos el judío puede ser (como se suele decir) un judío natural. Hay menos tensiones religiosas en Estados Unidos que en cualquier otra parte a lo largo de la historia -la tendencia nacional a vulgarizar la religión y experimentar con nuevas sectas ha permitido que el judío estadounidense pueda estar tranquilo-, para emerger desde la consciencia histórica a la consciencia judía contemporánea.

He hablado de creadores, y por tales entiendo no solo al poeta o al novelista, al pintor o al compositor, sino también al místico y al santo. Nuestra moderna educación racionalista nos pone en guardia contra cualquier pensamiento acerca de Dios. En nuestro tiempo decimos o pensamos que Dios es para las mujeres y para los niños. Acudimos eventualmente a lugares de culto, pero solo cuando sería de mal gusto no hacerlo. En la actualidad, ni el verdadero escritor ni el místico registran el almacén de la religión para su saqueo literario. No toman, dan. Nunca los veremos ni siquiera cerca de la sinagoga o de la iglesia; en muchos casos, en el pasado, se les ha prohibido entrar en la casa oficial de la plegaria. A los poetas y a los místicos siempre les han dado con la puerta en las narices; especialmente, la puerta de la iglesia.

Esta plena consciencia judía que es posible hoy, tanto en Estados Unidos como en Israel, es un modo de vida, por así decir. No necesariamente envuelta en rituales ni cosas por el estilo, aunque pueda serlo en algunos casos. No está necesariamente relacionada con la devoción, y puede que sea todo lo contrario. Estoy parafraseando a un filósofo judío 
moderno, Martin Buber -y espero no estar corrompiendo su pensamiento. Dijo: "La verdadera consagración del hombre es la consagración de lo humano que hay en él... En la vida, tal como el jasidismo [mística judía] la entiende y proclama, no hay distinción esencial entre los espacios sagrados y profanos, entre las acciones sagradas y profanas, entre las conversaciones sagradas y profanas". No estoy seguro de cuántos judíos aceptan este tipo de creencias, pero supongo que no son muchos. En cualquier caso, en mi ignorancia acerca de mi propia religión, este me parece el verdadero núcleo de la consciencia judía. Es antiascética y gozosa -los jasídicos bailan alocadamente con la Torah. "El hombre -dice Buber- no puede alcanzar lo divino elevándose por encima de lo humano; pero puede acercarse a Él volviéndose verdaderamente humano". En el último siglo, cuando el racionalismo alcanza todos los ámbitos, una doctrina como esta puede parecer una superstición salvaje. Para mí es como una bocanada de aire fresco. Es la forma más alta del Humanismo.

¿Qué tiene todo esto que ver con el problema del escritor judío estadounidense? Nada, probablemente. Sin embargo, observo un sorprendente parecido entre este humanismo místico y el humanismo secular estadounidense. Importa muy poco si el poeta o el novelista judío estadounidense escribe sobre el judío estadounidense (el buen artista raramente posee esa autoconsciencia); asimismo importa poco si vive como un judío en el sentido convencional de "vivir como"; lo que importa es si acepta o no las consecuencias de su judaísmo. No puede escapar a ellas en ningún caso, y no creo que deba sufrir esas consecuencias sino disfrutarlas.

Al escritor judío se le otorga una especie de libertad que es casi inconcebible. La combinación de judío y estadounidense no hace más que redoblar esa libertad.

La literatura moderna intenta perpetuar al judío tal como se refleja en la teología y la historia cristiana. Pero ese judío está tan muerto como el negro del minstrel show ${ }^{6}$. Ambas imágenes provienen de la época de la esclavitud. En la actualidad, el judío es libre en su patria mitológica, Israel; y es libre en Estados Unidos, la patria mitológica de la libertad. Creativamente ha comenzado a florecer como nunca antes, y el medievalismo de los Nuevos Clasicistas ${ }^{7}$ no podrá evitar ese florecimiento, por mucho que lo teman. Cualquier forma de libertad es un anatema para el clasicismo moderno. Ni siquiera el "verso libre" es del todo libre, según el poco fluido Eliot. El "judío librepensador" es, por supuesto, un grave peligro para todo lo que se oponga a la libertad.

\section{NOTAS}

1. [El New Criticism fue la corriente formalista e inmanentista que predominó en la crítica literaria y en las universidades estadounidenses desde la década de 1930 hasta la de 1960. Los ensayos de T.S. Eliot tuvieron una gran influencia sobre los "new critics".]

2. [The Poems of a Jew, New York, Random House, 1958.]

3. [En 1948 la Biblioteca del Congreso de Estados Unidos concedió a Pound el premio Bolligen, que se otorgaba ese año por primera vez, por los Cantos pisanos. El asunto causó un considerable revuelo debido a la abierta adhesión de Pound al fascismo, por el que fue juzgado y condenado al 
final de la Segunda Guerra Mundial. Shapiro (que propuso otorgar el premio a William Carlos Williams) y Katherine Garrison Chapin fueron los únicos miembros del jurado que votaron en contra. Por otra parte, el propio Shapiro iba a ganar ese galardón en 1969.]

4. [Durante la Segunda Guerra Mundial, Shapiro sirvió en las fuerzas estacionadas en el Pacífico Sur.]

5. [Shapiro concibe Estados Unidos e Israel como los únicos países donde el escritor judío tiene libertad de consciencia. Como es evidente, América Latina no formaba parte de su horizonte. Sería interesante pensar hasta qué punto la "identidad compuesta" a la que se refiere el autor esa que Europa nunca toleró y sí es posible, en cambio, en Estados Unidos e Israel- extiende su ámbito a los países de América Latina.]

6. [El minstrel show fue un tipo de espectáculo público, vigente desde 1830 aproximadamente hasta la década de 1910, en que comediantes blancos con la cara pintada de negro hacían mofa de los tópicos vinculados a los esclavos africanos y sus descendientes.]

7. [Con la fórmula New Classicists, Shapiro se refiere a las ideas que imperaron entre los seguidores de T.S. Eliot, quien había declarado -entre otras posiciones semejantes- que "el siglo XX ha visto el retorno del ideal del clasicismo", caracterizado por la "forma y la restricción en el arte, la disciplina y la autoridad en religión, y la centralización en el gobierno".] 